\title{
Identifying Lifetime and Occurrence of Intimate Partner Violence among Women in Sweden Seeking Emergency Care
}

\author{
Darcia Pratt-Eriksson 1,2*, Elisabeth Dahlborg-Lyckhage ${ }^{3}$, Caroline Lind ${ }^{4}$, \\ Katarina Sundberg 5 , Ingegerd Bergbom ${ }^{1}$ \\ ${ }^{1}$ Institute of Health and Care Sciences, Sahlgrenska Akademy, University of Gothenburg, Gothenburg, Sweden \\ ${ }^{2}$ Neurological Department, Huddinge, Karolinska University Hospital, Stockholm, Sweden \\ ${ }^{3}$ University West, Trollhättan, Sweden \\ ${ }^{4}$ Emergency Care, Emergency Department, Kungälv Hospital, Kungälv, Sweden \\ ${ }^{5}$ Psychiatric Care, Psychiatric Outpatient Clinic, Community Hospital Lilla Edet, Sweden \\ Email: ${ }^{*}$ darcia.pratt-eriksson@karolinska.se
}

Received 16 May 2015; accepted 26 June 2015; published 30 June 2015

Copyright (C) 2015 by authors and Scientific Research Publishing Inc.

This work is licensed under the Creative Commons Attribution International License (CC BY).

http://creativecommons.org/licenses/by/4.0/

(c) (i) Open Access

\section{Abstract}

Background: Sweden is known for its strong views on equality between men and women. Nevertheless, if one scratches the surface, one will realize that intimate partner violence (IPV) is a problem meriting much closer attention. Emergency nurses have an important role in identifying women who have IPV experiences. Objective: To identify and investigate the occurrence of reported experienced IPV during their lifetime among women seeking emergency care. Design: An explorative and comparative design was used based on answers on the Abuse Assessment Screen questionnaire and some demographic data. The data was described and analyzed using the Statistical Package for the Social Sciences version 21. Results: 0 f the 300 invited women visiting an emergency department in a small town, 234 completed the questionnaire. Of these $234,82(35 \%)$ reported having experienced emotional; physical or sexual violence and $31(13 \%)$ reported to being afraid of their partner. Of the women 181 had one child or more and $58(32 \%)$ of these reported having been abused. of all women, with four or more children, $75 \%$ (15) reported to have been abused, while only $25 \%$ (5) reported no abuse. Of the 82 women who reported having been abused 12 (15\%) reported being abused in the course of the year prior to pregnancy and $9(11 \%)$ during pregnancy, often several times. The main abuser was the woman's husband, boyfriend, cohabitating partner, ex-partner, or someone else who was seen as a relative, e.g., a parent. Conclusion: Using the questionnaire AAS may contribute to identifying victims of intimate partner violence and increasing health care practitioners' attentiveness concerning the type of injury, frequency of care seeking and actions that may indicate such violence lead to changes of the woman's situation.

\footnotetext{
*Corresponding author.
} 


\section{Keywords}

\section{Intimate Partner Violence, Pregnancy, Abuse, Women, Abuse Assessment Screen}

\section{Introduction}

World Health Organization (WHO), according to Krug, Dahlberg, Mercy and Lozano [1], has declared that Intimate Partner Violence (IPV) is one of the most common forms of violence against women and therefore represents a leading worldwide public health problem. National surveys in the late 1990s found the following IPV percentages: Barbados (30\%), Canada (29\%), Egypt (34\%), New Zealand (35\%), Switzerland (21\%) and United States 25\% [2]. In 2012, about 28,000 cases of violence against women were recorded in Sweden. The number of reported assaults has been on the increase for several years. Meanwhile, crime victim surveys show that a large part of the increase may be due to the fact that more crimes are actually reported [3]. The socioeconomic costs of IPV are estimated at between SEK 2695 million and SEK 3300 million per year. This health problem is often viewed as a private matter making it difficult to identify [1]. Most women seeking care at healthcare facilities usually seek care for other reasons rather than IPV. The injuries can be hidden or denied by the women out of fear or for other reasons. Many women seek care at trauma centers, acute care facilities and outpatient clinics for healthcare problems that may be indirect results of IPV. Healthcare personnel have a vital role in identifying IPV as they meet women in different healthcare settings when they are seeking care and treatment. Such a setting is the emergency department (ED) where patients seek care all days and nights. The majority of prior studies [4]-[6] examining IPV in ED settings has been conducted in large, urban tertiary care settings and may not reflect the experiences of women seen at community hospital EDs. Women who repeatedly seek care at the ED may lead to questions about the possibilities of previous experiences of abuse or ongoing abuse. Identifying IPV is of great importance as IPV is a crime but also leads to personal suffering, long-lasting health problems and social consequences for women, their children and their families [7]. Another reason for identifying women who have experienced or experience abuse is that abused women have more physical symptoms, are more frequent users of healthcare services, are more likely to suffer chronic pain, and have increased rates of depression, anxiety [4]-[8], low self-esteem, attempted suicide, abuse during pregnancy and pregnancyrelated complications [4] [7] [9]. Knowledge about women's previous experiences of abuse and ongoing abuse is important for providing accurate, appropriate and preventive care and help having a holistic perspective on the abused women and their situation. Caretta [8] emphasizes that nurses should develop health care planning and direct the health care concerns by using screening and offering support and assistance. Healthcare personnel may find it difficult to identify and/or ask about IPV, as the patient may feel fear, shame and guilt or frightened for being exposed that can jeopardize more violence from the partner. However, a self-administrated questionnaire may be seen as easier to hand over, but still it may be difficult to know what to do due to lack of knowledge and preparedness [10].

The Centers for Disease Prevention and Control (CDC) has a wide definition on IPV [11], which includes four types of behavior:

- Physical violence is when a person hurts or tries to hurt a partner by means of hitting, kicking or using another type of physical force.

- Sexual violence is forcing a partner to take part in a sex act when the partner does not consent.

- Threats of physical or sexual violence include the use of words, gestures, weapons or other means to communicate the intent to cause harm.

- Emotional abuse is threatening a partner or his or her possessions or loved ones, or harming a partner's sense of self-worth. The physical and psychological symptoms of violence which are evident in female victims can also be manifested in children who become eyewitnesses to the abuse of their mothers [7].

IPV is a sensitive subject and many healthcare professionals still see it as a private matter to be dealt with by the parties involved themselves. This may affect their ability to identify and provide care to victims of IPV. A nurse is usually the first healthcare professional to interact with an abused woman in the emergency room, physician's office, clinic or women's shelter. It is important that nurses are adequately prepared to identify women who have been abused and that they feel comfortable about asking questions about domestic violence [11]. Staff 
training is therefore important. Despite the evidence that women experiencing violence often seek help in an Emergency Department (ED), research indicates that women are not commonly asked about IPV when treated there [10] [11]. One explanation may be nurses' limited knowledge about the occurrence and signs of violence; another may be nurses' heavy workload which may limit the possibilities to establish a caring and trustful relationship with patients. In communities of affluence and privilege, victims of domestic violence face special challenges. If a victim has a high level of education, this often increases the shame and self-blame she feels about being in an abusive situation. There is also the mistaken belief, even among some healthcare professionals, that domestic violence does not occur among well-educated people [11]. The ED is usually the first place a woman seeks help in the healthcare system and it is plausible that many abused women passes through emergency care multiple times without being discovered. Very few Scandinavian studies [6] [12] have been conducted to identify abused women and also women with a history of being abused who are seeking emergency care. However, studies have been conducted concerning abused women in general psychiatric care [9]. Pregnant women are one of the many groups of women who seek care at ED. All women especially women in childbearing age and women with under age children should be assessed and questioned for IVP, as it has been found that IVP has long-lasting health problems for both women and their children [6] [9]. Therefore in this study we wanted to identify and investigate the occurrence of abused women and women with a history of IVP who were seeking care at an ED in a rural town close to a larger city by using a questionnaire. The aim was to identify and investigate the occurrence of reported experienced intimate partner violence during lifetime among women seeking emergency department by using a questionnaire. The study aimed to answer the following questions:

How many women seeking care at an emergency department at a small hospital near a city report having being abused?

Are there any differences between abused and non-abused women in terms of age, income, civil status, employment and number of children?

How many women reported having been abused in the course of the year prior to pregnancy and during pregnancy?

How many children were involved?

How many women reported being afraid of their partner and being forced to have sex?

\section{Method}

An explorative and comparative design was used based on data from a questionnaire and some demographic data as the purpose was to identify and explore the occurrence of IPV.

\subsection{Setting}

The study was carried out at an emergency department (ED) in a town, with about 40,000 inhabitants not far from a larger city in; a rural district in the Västra Götaland County in Sweden.

\subsubsection{Procedure}

During a 10-month period, a total of 22,759 individuals were registered in the emergency care (taken from the hospital records). Of these, 11,120 (48.9\%) were women and 11,639 were men, 9408 were registered as internal medicine cases, 11,725 as surgical cases and 1626 as psychiatric cases. Eligible subjects were all women visiting the ED regardless of reason for seeking care were approached, women who were at least 18 years old, had cognitive ability to answer questions, were not suicidal and had no other mental problems hindering their ability to respond to the questions. A total of 300 women were approached. Two trained nurses who had experience in the care of abused women invited all the women who visited the ED by giving information about the study and handing over the questionnaire and an envelope. The nurses emphasized that participation was voluntary and anonymous. The women were encouraged to submit the self administered questionnaire in a sealed envelope to ensure complete anonymity. The women in the present study were never asked about IPV in the presence of other people. Consequently, the questionnaire was given to the women when no other person was present. Prior to the study a one day information meeting about the nature of the study was held at the ED, where the questionnaire was introduced and the questions discussed. The nurses provided information to all women on follow ups and of the help available such as shelters and psychological help. 


\subsubsection{Participants}

Of the 300 women approached, 20 women declined to participate and 37 were not eligible due to illness preventing them from participating or due to timing problems. A total of 243 eligible women $(81 \%, r=18-89$ years old, mean age $48 \mathrm{SD}=17$, median 2 children) accepted to participate. However, 9 women did not answer the questions in the Abuse Assessment Screen, so 234 (response rate 78\%) women were included in the study.

\subsubsection{Data Collection}

Data was collected by using the Abuse Assessment Screen (AAS) questionnaire, developed by Soeken, McFarlene, Parker and Lominack [13] and some demographic data. The AAS is a five-item questionnaire used to assess the risk of abuse and has been used in many studies worldwide [12]-[17]. We have chosen to use a modified version by Stenson et al. [14] which was earlier tested in a Swedish population consisting of specific yes/no questions regarding emotional and physical abuse, abuse before and during pregnancy, and sexual abuse. To compare the answers from women in different stages of pregnancy, this was altered to "the year preceding this pregnancy". The question concerning "sexual abuse" was changed to: "Have you ever been forced to participate in or been subjected to sexual activity against your will?" The original version was: "Have you the last year." This question was changed to identify lifetime abuse as it has been found that IVP lead to long-lasting health problems [14]. The women were asked to reflect on the violence they had experienced from their partner/husband and indicate how much they were "affected" by various difficulties (see Box 1). Additional questions concerning age, relationship to abuser, number of children and employment status were asked. No piloting of the AAS modified version was conducted. In consistence with the study of Stenson et al. [14] professionals in the field of physical, emotional and sexual abuse was called on to analyze the items for content validity.

\subsection{Data Analysis}

Descriptive statistics and analysis were applied using Statistical Package for the Social Sciences version 21 (SPSS). Mean, standard deviation, median and range were used for describing the demographic data. Fisher's Exact, Chi Square and Non-Parametric tests were used for comparisons between groups. Statistical significance

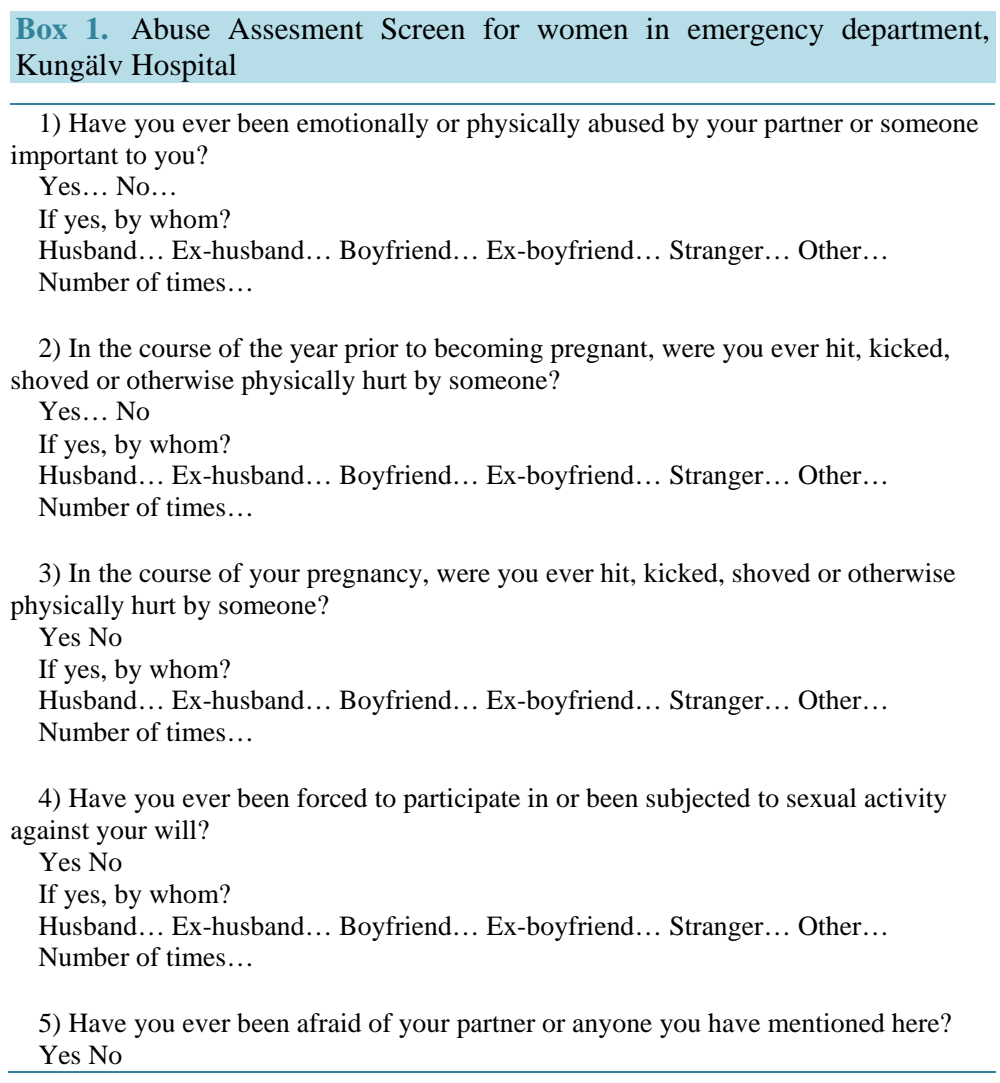


was defined as $\mathrm{p}<0.05$. Logistic regression was used to test the association between emotional and physical abuse and the variables age, marital status, employment status, yearly income and the age of the younger child. Odds Ratio and 95\% confidence interval (CI) was calculated.

\subsection{Ethical Considerations}

This study was part of a larger study on IPV against women in Sweden. Participation in the study was voluntary and all participants gave their approval for the study and the data protection explanations by completing and returning the questionnaire. The participating institution was told, prior to the study, that the study results would be published in an international scientific journal in anonymous form, to which it gave its consent. The participants were also told that the results would be presented in figures and tables and that no one would be able to trace any answers back to an identifiable individual. This study was approved by the Ethics Research Committee at Gothenburg University, Sweden (DNR: -009-06). The following principles guided the research: The consent of the women who constituted the research sample was obtained. Care was taken that the participants' identities would remain confidential and questions posed would not trigger reactions that were harmful to the patient's health. The safety of the respondents and the researchers was considered to be of paramount importance.

\section{Result}

Eighty-two of the 234 (35\%) women who answered the AAS reported having being abused emotionally and physically during their lifetime. The participants' demographic data is presented in Table 1. Abused women were significantly younger (43 years old) than non-abused (50 years old). Thirteen (16\%) of the abused women were 18 to 24 years old and 57 (69\%) were 25 to 54 years old. Twelve women (15\%) were older than 55 years old. Significant $(\mathrm{p}=0.003$ ) association was found when age and being abused emotionally and physically were assessed, $(\mathrm{OR}=0.975 ; 95 \% \mathrm{CI}=0.959,0.992)$, which indicated lower odds for being abused when older.

As can be seen in Table 1, the abused women's income varied between very low incomes (325 SEK/year) to a relatively normal income (312,000 SEK/year), while it varied between 30,000 and 600,000 SEK/year among women not abused. Significantly fewer abused women were not married compared to non-abused women (p = 0.000). More non-abused women were employed or studied compared to abused women $(p=0.005)$. This significant relationship was also found when investigating the relationship between being employed /studying and no abuse. There was no significant difference between abused married women and non abused married women. There was however a greater risk for being abused when not married $(\mathrm{OR}=1.31$; 95\% CI $=0.146,3.80)$. Being housewife and unemployment (OR $=5.331$; 95\% CI $=1.41,22.812$ ) seemed to be associated with higher odds of being abused emotionally and physically.

One woman was identified as having been abused in a lesbian relationship, while 21 (26\%) had been abused

Table 1. Demographic data for respondents, abused and non-abused women.

\begin{tabular}{|c|c|c|c|}
\hline Demographics & Abused women $n=82$ & Non-abused women $n=152$ & All women $n=234$ \\
\hline $\begin{array}{l}\text { Age in years: mean (SD); MD; range; } \\
{ }_{n} \mathrm{n}=81 \text { abused/150 non-abused }\end{array}$ & $43(15.2) ; 44 ; r=18-78^{* *}$ & 50 (17.3); 51; r = $18-89$ & 48 (16.7); 47.5; r = 18 - 89 \\
\hline Employed/student n (\%) & $33(27)^{*}$ & $88(73)$ & 121 \\
\hline Unemployed, retired, housewife n (\%) & $44(45)$ & $53(55)$ & 97 \\
\hline $\begin{array}{l}\text { Salary SEK/year: mean; range; } \\
{ }^{\#} n=23 \text { abused/44 non-abused }\end{array}$ & 211,$831 ; r=325-312,000$ & 253,$908 ; r=30,000-600,000$ & 241,$237 ; r=325-600,000$ \\
\hline Women with no children/with children & $23 / 58$ & 29/123 & $52 / 181$ \\
\hline Married n (\%) & $20(18.5)$ & $88(81.5)^{* * *}$ & 108 \\
\hline Cohabiting n (\%) & $17(45)$ & $21(55)$ & 38 \\
\hline Living alone/single n (\%) & 33 (59) & $23(41)$ & 56 \\
\hline
\end{tabular}

${ }^{*}=$ p. $005,,^{* *}=$ p.001, ${ }^{* * *}=$ p.000, ${ }^{\#}=$ the number of women who answered the question. 
by a husband, boyfriend or partner (current or former). Seventeen (21\%) reported having been abused by someone else and six reported having been abused by an unknown person. "Someone else" was seen in this study as a close relative (such as a father, mother, stepfather, cousin) or a friend. Five women (6\%) revealed having been abused several times by a "stranger" or someone else. Of these five women three disclosed being first abused by a parent, then by a partner and then by a son. Twenty-seven (33\%) of the abused women were retired or on early retirement.

\subsection{Abused Women and Their Children}

Fifty-two (23\%) women (23 of the abused women and 29 of the non-abused) reported not having children. These women were between 18 and 24 years old. Of the women (25 - 89 years old) who had children $(\mathrm{n}=181)$, 123 women (68\%) had one child or more (on average 2 children) and reported not having been abused, while 58 (32\%) reported having been abused. It was found that more women who were abused $(n=15)$ had 4 or more children compared to non-abused women $(n=5$; Chi square $\mathrm{p}<0.000)$. In total, the 181 women had 241 children $(r=1-7$ children). 80 children of abused women were younger than 18 years old and were living at home. When examining the association between being abused emotionally and physically and the variable "age of the youngest child" it was significantly $(\mathrm{p}=0.008)$ associated with lower odds of being abused $(\mathrm{OR}=0.969$; $95 \% \mathrm{CI}$ $=0.947,0.991$ ) indicating that the younger the child the lower risk.

\subsection{Violence Prior to and during Pregnancy}

Of the 234 women who answered the questionnaire, 174 women answered the question about being abused/not being abused in the course of the year prior to and during pregnancy. Twenty-four (29\%) of the 82 who reported having being abused reported having been abused in the year prior to becoming pregnant and 16 (20\%) during pregnancy. The women disclosed that they had been hit, kicked, shoved or otherwise physically hurt by someone in the course of the year prior to and during pregnancy. The abuser was a husband, ex-husband, boyfriend or someone else. Several women reported being abused by more than one person (Table 2).

\subsection{Sexual Abuse and Violence}

A total of 187 women answered the question about being forced to have sex. Of these 187 women, 54 (29\%) reported having been forced to have sex and 133 reported not having been forced. Nineteen of the women (35\%) who had been forced to have sex reported being forced several times. Twenty-three of the abused women identified "Someone else" as the abuser while 21 (39\%) identified their husband and/or boyfriend (Table 2). Ten of the abused women (19\%) had been raped both by someone they knew and by a stranger several times at different occasions. Of these ten women, four disclosed experiencing sexual abuse as a child. Three of these four women (4\%) disclosed that they had been forced into incestuous behavior by their father. Two of the women had been gang raped several times. The women were aged between 37 and 78 years old. Of the 54 women who reported having been forced to have sex, 18 (33\%) had been forced into sexual activity in the course of the year prior to becoming pregnant.

Table 2. Number of women abused before and during pregnancy, and sexual abuse, the frequency and the abuser.

\begin{tabular}{|c|c|c|c|c|c|c|}
\hline & n (\%) & $\begin{array}{l}\text { On one } \\
\text { occasion }\end{array}$ & $\begin{array}{l}\text { More than two } \\
\text { occasions }\end{array}$ & $\begin{array}{l}\text { Husband/ } \\
\text { boyfriend/partner } \\
\text { or "ex-husband" }\end{array}$ & $\begin{array}{l}\text { Husband and } \\
\text { other person }\end{array}$ & $\begin{array}{l}\text { Someone } \\
\text { else/unknown }\end{array}$ \\
\hline $\begin{array}{c}\text { Abused before pregnancy }{ }^{1} \\
\text { Women who answered }=174\end{array}$ & 24 (29) & 3 & 9 & 14 & 1 & 8 \\
\hline $\begin{array}{c}\text { Abused during pregnancy }{ }^{2} \\
\text { Women who answered }=174\end{array}$ & $16(20)$ & 3 & 6 & 13 & 1 & 2 \\
\hline $\begin{array}{c}\text { Forced to have sex }{ }^{3} \\
\text { Women who answered }=187\end{array}$ & $54(67)$ & 7 & 19 & 21 & 0 & 23 \\
\hline
\end{tabular}

${ }^{1}=$ Of the 24 women who had been abused prior to pregnancy, 12 disclosed how many times they had been abused before pregnancy; ${ }^{2}=$ Of the 16 women who had been abused during pregnancy 9 disclosed how many times they had been abused during pregnancy; ${ }^{3}=26$ women disclosed how many times they had been forced to have sex and 44 disclosed by whom. 


\subsection{Feeling Fear of Their Partner}

A total of 186 of the women (79.5\%) answered the question "Are you afraid of your partner or anyone". Thirtyone (38\%, mean age 43 years old) of the women reporting having been abused $(n=82)$ expressed fear of their partner. Of these 31 women, 27 (87\%) disclosed having experienced physical and psychological abuse during pregnancy and 9 women (29\%) disclosed having been afraid of their partner in the course of the year prior to pregnancy.

\section{Discussion}

This is the first Swedish study to our knowledge which identified and investigated the occurrence of IPV experienced at some point during their lifetime by women seeking care at an ED. In this study, it was found that more unemployed women reported being abused than employed or studying women. The difference between the lowest and the highest salary of abused women and non-abused women was great. It is possible that those women who reported very low annual salary did not estimate social financial allowance as salary, which usually is connected to employment. It has to be noted that women's income and employment reflects the situation at time for the ED visit. As the questions about IPV concerned previous and ongoing abuse, the situation could have been another at time for the IPV. However the figures concerning income and employment are interesting. These may indicate that some women seeking care at ED may have long-lasting health problems, which also have been found by Campbell 2002 [18] and Campbell and Lewandowski 1997 [19]. Maybe these health problems caused by IPV make them unable to work or work full-time as the lowest income was found in the group of abused women. Abused women were significantly younger than non-abused women who are consistent with a British study [5]. One explanation in relation to employment and having one's own income may be that over the last few years many young people (18 - 26 years old) in Sweden have been both out of school and unemployed. This socio-economic context may make it difficult for young people to enter into sustainable and lasting relationship, to marry and start a family. Nonetheless, it may be questioned and discussed whether employment, studies and work are important factors for preventing IPV. It is possible that the occurrence of IPV in relationships where both woman and man are employed and enjoy a satisfactory financial situation may be the same as for unemployed couples, but these women may have the possibility in their work to stay home when being injured due to IPV or they seek help for their injuries at private clinics and not emergency rooms in hospitals, where they may be seen by others.

About one-third of the abused women were retired or on early retirement. One reason for early retirement may be consequences of long-lasting IPV, heavy work often with low income, or psychiatric/psychological problems or chronic diseases as a consequence of IPV. Therefore it would be interesting to further study retired women's health including the occurrence of IPV.

The main perpetrator identified in this study was the women's husband, boyfriend/partner or ex-husband. A small number of women disclosed having been abused by someone they knew, such as a relative. In a few cases, women had been abused by an unknown person. An important factor identified in this study is the high number of children with mothers who are or have been an object of IPV. Children who have been exposed to domestic violence are at risk of developing mental health problems such as depression, anger, aggression or anxiety and it affects adult health [19]-[21]. A small number of women included in our study also disclosed having experienced childhood abuse. Women, who had experienced both childhood abuse and abuse as an adult, undergo both a significantly higher number of surgeries and more major surgeries than women with no history of abuse [20] [22].

Violence has negative influence on women during pregnancy. In a Turkish study, lower weight was found more often among abused women than among non-abused women, which was considered to be associated with emotional dysfunction and psychological stress [16] [22]. This study shows a decrease in violence during the pregnancy which is consistent with the study by Bagcioglu, Vural, Karababa, Aksin and Selek [16]. We fear many women may use pregnancy as a tool to stop the violence in an abusive relationship, because during pregnancy the violence decreases. Pregnancy may be used as a shield to protect her from further abuse. Another reason why the violence may decrease is that a child may serves as a symbol of a good relationship and of the parents' commitment to each other; the child becomes a project that bonds. Several women in this study revealed having been sexually abused prior to becoming pregnant. Sexual abuse is associated with higher risk of contracting sexually transmitted diseases, such as HIV/AIDS, either through forced unprotected sex or through the increased likelihood of risky sexual behavior [23]-[26]. According to a European Union study [27], Sweden has 
one of the highest rates of reported rape in Europe and a low conviction rate, but the definition of rape is quite different from country to country.

Several women in this study disclosed being afraid of their partner/husband or cohabitating partner. We believe that some woman may stay with her abuser because she thinks the lifestyle is "normal", or she may have developed a form of "Stockholm syndrome" and identifies and agrees with the abuser that she is bad, stupid or deserves what is happening to her as seen in other studies [28]. Healthcare professionals in EDs should be expected to ask about possible abuse and to promote satisfactory communication with female patients seeking care or using a questionnaire for detecting IPV. They also have to recognize signs of health problems that could be associated with experiences of IPV. Communication and a caring relationship are of vital importance in order to create a trustful and secure situation, which may for example reduce reported feelings of isolation. However, team support and education is needed so that the health care personnel knows what to do and how they could help the woman as highlighted by Sundborg et al. [29]. Despite held social beliefs that women do not leave abusive partners or start another relationship with an abusive partner McDonald and Dickerson [30] found that women can leave and develop a belief in their own ability to live their lives even if mistrust and control of others remained regardless of how long they had been out of the abusive relationship.

The AAS questionnaire was found to be a useful questionnaire for identifying IPV in an emergency setting, which was also seen as easy to handle by the nurses who should invite participants. However, it is possible and plausible that all women who had or was abused were not detected. We also wanted to know the occurrence of IPV, sexual abuse and abuse in connection with pregnancy, in a small town, situated close to a larger city. Previous studies of pregnant and non-pregnant women have shown that AAS is an effective tool for identifying IPV [13]-[17] [31]. No other questionnaire in Swedish language with questions about abuse and pregnancy was available. Soeken, McFarlane and Parker [13] report an indicated internal reliability and construct validity based on the comparison of results with other national surveys.

This study has several limitations. There was some internal dropout due to some women not answering some of the questions. In some cases relatives were close to the patient all the time and therefore it was impossible to hand over the questionnaire. As it was important to not cause harm but to protect women from unknown consequences the nurses who invited the patients to participate in the study, had to in each case assess the situation and to listen to their intuition. This shows that IVP is a sensitive topic making it difficult to assess violence, but by using the AAS at least some women with lifetime abuse were identified. This study does not represent the entire Swedish population none the less; it gives a picture of the occurrence of women with ongoing or previously experienced IPV in a small town.

\section{Conclusion}

Emergency care professionals are in contact with abuse women who have both hidden and discovered abuse. Repeated readmissions can be signs of ongoing or previous IPV and therefore may be seen as a cry for help and serious long lasting health problems. Therefore it is important to use strategies such as a self-administrated questionnaire that may detect health problems and injuries connected to ongoing or previous IPV. In emergency care the healthcare professionals need to be prepared with a positive and caring attitude, and communicative skills that may increase the possibilities for abused women to bring up IPV.

\section{Acknowledgements}

We thank the women for participating in the study and the Swedish Society of Trauma Nurses and Neurological Clinic at the Karolinska University Hospital for providing the funding needed for the study. The authors thank Patrick Reis for his editing and proofreading assistance for this article and the Institute of Health and Care Sciences, Sahlgrenska Academy, University of Gothenburg for financial support.

\section{Conflict of Interest}

The authors declare that they have no competing interests.

\section{Authors' Contribution}

Darcia Pratt-Eriksson (DPE), Elisabeth Dahlborg Lyckhage (EDL) and Ingegerd Bergbom (IB) designed the 
study. Katarina Sundberg (KS) and Caroline Lind (CL) collected the study data. DPE, EDL and IB performed all statistical analyses and interpreted the findings. All authors read and approved the final manuscript.

\section{References}

[1] Krug, E.G., Dahlberg, L.L., Mercy, J.A., Zwi, A.B. and Lozano, R. (Eds.) (2002) World Report on Violence and Health. World Health Organization (WHO), Geneva, 3-21.

[2] Heise, L., Ellsberg, M. and Gottemoeller, M. (1999) Ending Violence Against Women. Population Reports, Series L, No.11. http://www.vawnet.org/assoc_files_vawnet/populationreports.pdf

[3] National Council of Crime Prevention (Brå) (2015) The Swedish Crime Survey 2014 (NTU). English Summary of Brå Report 2015:1, 1-14.

[4] Alhabib, S., Nur, U. and Jones, R. (2010) Domestic Violence Against Women: Systematic Review of Prevalence Studies. Journal of Family Violence, 25, 369-382. http://dx.doi.org/10.1007/s10896-009-9298-4

[5] Boyle, A. and Todd, C. (2003) Incidence and Prevalence of Domestic Violence in a UK Emergency Department. Emergency Medicine Journal, 20, 438-442 http://dx.doi.org/10.1136/emj.20.5.438

[6] Bergman, B. and Brismar, B. (1991) A 5-Year Follow-Up Study of 117 Battered Women. American Journal of Public Health, 81, 1486-1489. http://dx.doi.org/10.2105/AJPH.81.11.1486

[7] U.S. Preventive Services Task Force (2013) Screening for Intimate Partner Violence and Abuse of Elderly and Vulnerable Adults: U.S. Preventive Services Task Force Recommendation Statement. http://annals.org/article.aspx?\&year=2013\&volume=158\&page $=478$

[8] Carretta, C.M. (2008) Domestic Violence: A Worldwide Exploration. Journal of Psychosocial Nursing and Mental Health Services, 46, 26-35. http://dx.doi.org/10.3928/02793695-20080301-02

[9] Malecha, A. (2003) Screening for and Treating Intimate Partner Violence in the Workplace. AAOHN Journal, 51, 310316.

[10] Örmon, K., Torstensson-Levander, M., Sunnqvist, C. and Bathsevani, C. (2014) Vulnerable and without Protection: Lifetime Experiences of Abuse and Its Influence on Mental Ill Health: An Interview Study among Swedish Women within General Psychiatric Care. Open Journal of Nursing, 4, 34-41. http://dx.doi.org/10.4236/ojn.2014.41006

[11] Saltzman, L.E., Fanslow, J.L., McMahon, P.M. and Shelley, G.A. (2002) Intimate Partner Violence Surveillance: Uniform Definitions and Recommended Data Elements (Version 1.0). Centers for Disease Control and Prevention, National Center for Injury Prevention and Control, Atlanta.

[12] Wathen, N. and MacMillan, H. (2012) Partner Violence Screening and Women's Quality of Life. Letters. Journal of American Medical Association, 308, 2334-2336.

[13] Soeken, K.L., McFarlane, J., Parker, B. and Lominack, M.C. (1998) The Abuse Assessment Screen: A Clinical Instrument to Measure Frequency, Severity, and Perpetrator of Abuse against Women. In: Campbell, J.C., Ed., Empowering Survivors of Abuse: Health Care, Battered Women, and Their Children, SAGE Publications, Inc., Thousand Oaks, 195-203.

[14] Stenson, K., Heimer., G., Lund, C., Nordström, M.L., Sarinnen, H. and Wenker, A. (2003) Lifetime Prevalence of Sexual Abuse in a Swedish Pregnant Population. Acta Obstetricia et Gynecologica Scandinavica, 82, 529-536. http://dx.doi.org/10.1034/j.1600-0412.2003.00111.x

[15] Lawoko, S., Sanz, S., Helström, L. and Castren, M. (2011) Screening for Intimate Partner Violence against Women in Healthcare Sweden: Prevalence and Determinants. ISRN Nursing, 2011, 1-7. http://dx.doi.org/10.5402/2011/510692

[16] Bagcioglu, E., Vural, M., Karababa, I.F., Akşin, M. and Selek, S. (2014) Decrease in Domestic Violence during Pregnancy: A Study from Turkey. Journal of Interpersonal Violence, 29, 203-216. http://dx.doi.org/10.1177/0886260513505147

[17] Laisser, R.M., Nyström, L., Lindmark, G., Lugina, H.M.I. and Emmelin, M. (2011) Screening of Women for Intimate Partner Violence: A Pilot Study Intervention at an Outpatient Department in Tanzania. Global Health Action, 4, 7288. http://dx.doi.org/10.3402/gha.v4i0.7288

[18] Campbell, J. (2002) Health Consequences of Intimate Partner Violence. The Lancet, 359, 1331-1336. http://dx.doi.org/10.1016/S0140-6736(02)08336-8

[19] Campbell, J. and Lewandowski, L. (1997) Mental and Physical Health Effects of Intimate Partner Violence on Women and Children. Psychiatric Clinics of North America, 20, 353-374. http://dx.doi.org/10.1016/S0193-953X(05)70317-8

[20] Lukasse, M., Vangen, S., Øian, P., Kumle, M., Ryding, E.L. and Schei, B. (2010) Childhood Abuse and Fear of Childbirth-A Population-Based Study. Birth, 37, 267-274. http://dx.doi.org/10.1111/j.1523-536X.2010.00420.x

[21] Mezey, G.C. and Bewley, S. (1997) Domestic Violence and Pregnancy. British Medical Journal, 314, 1295. 
http://dx.doi.org/10.1136/bmj.314.7090.1295 http://www.ncbi.nlm.nih.gov/pmc/articles/PMC2126542/

[22] Jaquier, V., Hellmuth, J.C. and Sullivan, T.P. (2013) Posttraumatic Stress and Depression Symptoms as Correlates of Deliberate Self-Harm among Community Women Experiencing Intimate Partner Violence. Psychiatry Research, 206, 37-42. http://dx.doi.org/10.1016/j.psychres.2012.09.020

[23] Van Dulmen, M.H.M., Klipfe, K.M., Mata, A.D., Schinka, K.C., Claxton, S.E., Swahn, M.H. and Bossarte, R.M. (2012) Cross-Lagged Effects between Intimate Partner Violence Victimization and Suicidality from Adolescence into Adulthood. Journal of Adolescent Health, 51, 510-516. http://dx.doi.org/10.1016/j.jadohealth.2012.02.015 http://www.jahonline.org/article/S1054-139X\%2812\%2900097

[24] Pratt-Eriksson, D., Bergbom, I. and Dahlborg-Lyckhage, E. (2014) Don’t Ask Don’t Tell: Battered Women Living in Sweden Encounter with Healthcare Personnel and Their Experience of the Care Given. International Journal of Qualitative Studies on Health and Well-Being, 9, 1-7. http://dx.doi.org/10.3402/qhw.v9.23166

[25] Mittal, M., Senn, T.E. and Carey, M.P. (2012) Intimate Partner Violence and Condom Use among Women: Does the Information-Motivation-Behavioral Skills Model Explain Sexual Risk Behavior? AIDS and Behavior, 16, 1011-1019. http://dx.doi.org/10.1007/s10461-011-9949-3

[26] Stockman, J.K., Lucea, M.B. and Campbell, J.C. (2013) Forced Sexual Initiation, Sexual Intimate Partner Violence and HIV Risk in Women: A Global Review of the Literature. AIDS and Behavior, 17, 832-847. http://www.ncbi.nlm.nih.gov/pmc/articles/PMC3586980 http://dx.doi.org/10.1007/s10461-012-0361-4

[27] Kelly, L. and Lowett, J. (2009) Different Systems, Similar Outcomes? Tracking Attrition in Reported Rape Cases in Eleven Countries. Child and Woman Abuse Studies Unit. http://www.cwasu.org/publication_displayasp?pageid=PAPERS\&type=1\&pagekey=44

[28] Stöcki, H., Hertlein, L., Friese, K. and Stöcki, D. (2010) Partner, Workplace, and Stranger Abuse during Pregnancy in Germany. International Journal of Gynecology \& Obstretics, 111, 136-139. http://dx.doi.org/10.1016/j.ijgo.2010.06.014

[29] Sundborg, E.M., Saleh-Stattin, N., Wändell, P. and Törnkvist, L. (2012) Nurses’ Preparedness to Care for Women Exposed to Intimate Partner Violence: A Quantitative Study in Primary Health Care. BMC Nursing, 11, 1. http://dx.doi.org/10.1186/1472-6955-11-1

[30] McDonald, P.W. and Dickerson, S. (2013) Engendering Independence While Living with Purpose: Women's Lives after Leaving Abusive Intimate Partners. Journal of Nursing Scholarship, 45, 388-396. http://dx.doi.org/10.1111/jnu.12044 http://www.ncbi.nlm.nih.gov/pubmed/24034275

[31] McFarlane, J., Parker, B. and Cross, B. (2001) Abuse during Pregnancy: A Protocol for Prevention and Intervention. 2nd Edition, March of Dimes, White Plains. 